\title{
Laparoscopic Varicocelectomy - Initial Experience at Our Tertiary Care Centre
}

\author{
Atif Naeem Raja ${ }^{1}$, Mir Mujtaba Ahmad ${ }^{2 *}$, Raja Nadeem² ${ }^{2}$ Irfan Nazir Mir ${ }^{1}$ and Hilal Awani ${ }^{1}$ \\ ${ }^{1}$ Department of Surgery, GMC, India \\ ${ }^{2}$ Department of Surgery, HIMSR, India
}

Submission: November 29, 2016; Published: December 08, 2016

*Corresponding author: Mir Mujtaba Ahmad, Senior Resident, Department of Surgery, HIMSR, New Delhi, India

\begin{abstract}
Object: To evaluate the outcome of laparoscopic varicocelectomy in terms of perioperative and postoperative parameters with special emphasis on improvement in symptoms, semen analysis and restoration of fertility.

Background: Varicoceles demanding treatment can be managed by various options like open varicocelectomy, laparoscopic varicocelectomy or by embolisation. Laparoscopic varicocelectomy confers minimum morbidity, shorter hospital stay and early return to work with the advantage of treating bilateral varicoceles without any additional incisions hence can be considered as a preferable surgical technique in the management of symptomatic varicoceles.
\end{abstract}

Material and Methods: This prospective study was conducted in the department of General surgery, GMC, Srinagar over a period of two years spanning June 2010 to May 2012. All the patients with clinically significant varicoceles were included in this study. The patients underwent transperitoneal 3-port laparoscopic high ligation of testicular vein.

Results: A total of 39 patients underwent laparoscopic varicocelectomy without any morbidity or conversion to open. The mean operating time to complete the procedure was $48.4 \mathrm{~min}$. There was no significant blood loss with minimal need of analgesic in the post operative period. There were no major postoperative complications. The mean hospital stay was 1.65 days. Most of the patients resumed their routine work within 3 days of surgery. Only one patient developed recurrence. Semen analysis showed improvement in terms of improved sperm concentration (69.4\%) and improved motility (55.5\%).

Conclusion: Our study concludes that Laparoscopic varicocelectomy is a safe, feasible and effective procedure for varicoceles meriting treatment with favorable outcomes in terms of cosmesis, pain, improvement of symptoms and restoration of semen parameters and fertility henceforth.

Keywords: Laparoscopic; Varicocelectomy; Semen Analysis; Fertility

\section{Introduction}

Varicocele is defined as an abnormal dilatation and tortuousity of veins of pampiniform plexus, found in approximately $15 \%$ of male adolescents, with a marked left sided predominance [1]. Varicocele is associated with a time dependent testicular growth arrest in adolescents and adult males [1]. Thereis a clear association between varicocele, infertility, and testicular growth arrest [2]. It is also known that varicocelectomy can reverse growth arrest in adolescents and show improvement in sem8 en quality. Most of the adolescent varicoceles are asymptomatic and are discovered on routine physical examination. Some cases present with inguinal or scrotal aching discomfort or dragging pain. Classical description of varices is the consistency of "Bag of Worms" that decompresses when patient is in supine position
[3]. Varicocele is a clinical diagnosis established by physical examination.

Patients with varicocele undergo a detailed medical and reproductive history, semen analysis and radiographic tests such as real time scrotal ultrasonography and color Doppler ultrasonography, spermatic venography, and thermography. Typically, a Doppler ultrasound examination demonstrating veins $3.5 \mathrm{~mm}$ or larger in diameter with reversal of venous flow with Valsalva maneuver is consistent with diagnosis of varicocele [4]. If varicocele is not causing any symptoms of pain and infertility is not an issue, no treatment is warranted. Mild discomfort can be managed by wearing an athletic supporter or snug-fitting underwear during strenuous activity or exercise. 
Treatment of varicocele is indicated in following conditions:

i. Adolescent [age 12-18 years] with large varicocele and evidence of decreased testicular size.

ii. Any person with varicocele induced testicular pain

iii. Varicocele in men who are sub fertile or infertile.

Various treatment modalities for varicoceles are:

a) Open surgical procedures: Three open surgical approaches are currently used- Subinguinal [Marmar], Inguinal [Ivanissevich], and Retroperitoneal [Palomo].

b) Laparoscopic varicoceletomy [5]

c) Percutaneous embolization [6]

\section{Methodology}

This study was conducted in post graduate department of surgery, Govt. Medical College Srinagar for a period of 2 years spanning June 2010 to May 2012.This was a prospective study and a total of 39 patients with clinically significant varicocele were included in this study. All the patients were analyzed as follows:
a. History taking
b. General physical examination
c. Systemic examination
d. Local examination
e. Baseline investigation

Special investigations like:
a. Scrotal color Doppler ultrasound
b. Semen analysis
i. Operative findings
ii. Operative time
iii. Post operative observations and complications

Patients were followed up on weekly/fortnightly and monthly basis in the follow-up clinic upto a period of 3 months. All the patients in our study were treated by laparoscopic varicocelectomy and outcome of the technique was analysed in terms of operating time, semen analysis results, and complications.

\section{Surgical technique}

Laparoscopic varicocelectomy: Patients were operated in supine position under general anesthesia. A urinary catheter was inserted after the induction of anesthesia to evacuate the bladder or the patient was asked to void just before shifting to operation room. Post induction naso gastric tube was passed to decompress the stomach. A varess needle for creation of pneumoperitoneum was introduced through a small infra umblical incision. Then, the abdomen was inflated with $\mathrm{CO} 2$ gas, pressure maintainted between 12 to $14 \mathrm{~mm} \mathrm{Hg}$. The head end of bed was lowered 150 to 300 to displace the bowel away from the lower quadrants of abdomen. Veress needle was replaced by 10 $\mathrm{mm}$ trocar and cannula after enlarging the skin incision.

$10 \mathrm{~mm}$ telescope was inserted through the $10 \mathrm{~mm}$ trocar. Under direct vision $2 \mathrm{nd}$ and $3 \mathrm{rd}$ trocars $(10 \mathrm{~mm}$ and $5 \mathrm{~mm}$ ) were bilateraly introduced through the incisions located in the $2 / 3 \mathrm{rd}$ distance from umblicus to anterior superior iliac spine. Grasper and scissors were used to put two perpendicular incisions into the peritoneum overlying the internal spermatic veins. The vascular mass was lifted to separate arterial and lymphatic components from the veins. Then the veins were ligated by clips or by intracorporeal knotting. After verifying the hemostasis, trocars were removed and incision sutured. Antiseptic laparoscopic dressings were applied.

\section{Results}

A total of 39 patients were included in the study with symptomatic varicoceles demanding surgery. Majority of patients were in 2 nd and 3rd decade of life. Most of the patients were having swelling and dragging sensation of testis on affected side. Majority of patients were having grade III and grade II varicocele at the time of surgery. All the patients underwent laparoscopic varicocelectomy with a mean operative time of 48.4 minutes with most of the patients having minimal pain, no major post operative complications. Average hospital stay was 1.65 days and mean time to resume normal activities was 4.4 days (Table 1). Patients were followed up on weekly/fortnightly and monthly basis in the follow-up clinic upto a period of 3 months.

Table 1: Average hospital stay was 1.65 days and mean time to resume normal activities was 4.4 days.

\begin{tabular}{|c|c|}
\hline AGE (years) & \\
Range & $15-45$ \\
Mean & 24.4 \\
\hline & No. of Patients \\
(\%age)
\end{tabular}




\section{Open Access Journal of Surgery}

\begin{tabular}{|c|c|}
\hline DURATION OF SURGERY (minutes) & \\
\hline Range & $20-60$ \\
\hline Mean & 48.4 \\
\hline \multicolumn{2}{|l|}{ SEVERITY OF PAIN (VAS) } \\
\hline Absent & Nil \\
\hline Mild & $24(61.5)$ \\
\hline Moderate & $14(35.9)$ \\
\hline Severe & $1(2.5)$ \\
\hline \multicolumn{2}{|l|}{ POST-OPERATIVE COMPLICATIONS } \\
\hline Nausea \& vomiting & $06(15.38)$ \\
\hline Shoulder tip pain & $03(7.69)$ \\
\hline Wound infection & Nil \\
\hline Headache & Nil \\
\hline Urinary retention & Nil \\
\hline \multicolumn{2}{|l|}{ HOSPITAL STAY(Days) } \\
\hline $1-2$ & $35(89.8)$ \\
\hline $2-4$ & $4(10.2)$ \\
\hline$>4$ & Nil \\
\hline \multicolumn{2}{|l|}{ RETURN TO NORMAL WORK(Days) } \\
\hline $1-2$ & $3(7.7)$ \\
\hline $3-5$ & $26(66.6)$ \\
\hline 6-10 & $10(25.6)$ \\
\hline$>10$ & Nil \\
\hline \multicolumn{2}{|l|}{ FOLLOW UP (3weeks to 9 months) } \\
\hline \multicolumn{2}{|l|}{ A. Scrotal symptoms $(n=34)$} \\
\hline Complete relief & $31(91.1)$ \\
\hline Residual pain & $2(5.8)$ \\
\hline Recurrence & $1(2.5)$ \\
\hline \multicolumn{2}{|l|}{ B. Infertiliy $(n=5)$} \\
\hline Improved sperm parameters & $4(80)$ \\
\hline Pregnancy & $1(20)$ \\
\hline
\end{tabular}

Special emphasis was given on residual pain, return to routine work, recurrence as assessed by clinical examination and Doppler USG, and satisfaction of individual patients with respect to the outcome of procedure done. In all the patients post operative semen analysis was done three months after varicocelectomy procedure and results were compared with preoperative semen analysis reports. There was remission of scrotal symptoms in $97 \%$ patients and improved of semen parameters in $80 \%$ of patients and conformation of pregnancy in 1 patient. There was one recurrence in our study group accounting to a recurrence rate of about $2.5 \%$ that was observed in 3 month of follow up.

\section{Discussion}

The incidences of varicoceles are 15\% in normal population. However, it has a prevalence of $34-40 \%$ in infertile males. Most palpable varicoceles are left sided although right sided and bilateral varicoceles do occurs. The progressive and deleterious effect upon the testicular growth and reproductive function due to varicoceles is well documented. The age group involved is varied in range of 8-45 years [2]. Majority of patients have scrotal complaints in form of scrotal swelling and pain followed by infertility [7]. The technique of laparoscopic varicocelectomy has gained wide acceptance since its introduction by Winfield and his colleagues in 1991 [6]. Reports have suggested that laparoscopic approach not only carried lesser morbidity, less post-operative pain, early return to routine work, but also had the same success rate as open procedures.

In our series average operation time was 48.4 minutes with the range of 30 - 60 minutes. The average operating time for laparoscopic varicocelectomy after the training period has been completed was 44 minutes in series by Jimenez Garrido A et al. [8]. The operating time required for laparoscopic surgery is significantly longer than that for the open surgery [9]. Majority of patients perceived minimal pain and had mild grade of pain as per VAS scale, analgesic requirement of patients was 2 to 3 doses of analgesics in the post operative period with an average of 1.55 doses per patient $[7,10]$. We observed an average hospital stay of 39.6 hours .In our series post-operative stay was comparable to other available series in literature. Osman $\mathrm{T}$ et al. [11] reported that the post-operative hospital stay was 52 hours and 8.4 hours in open and laparoscopic varicocelectomy group, respectively. Zain $\mathrm{H}$ Al-Sharief et al. $[7,10]$ in their series reported hospital stay of 2 days it was observed that patients who were from city or nearby areas happily accepted early discharge from the hospital, whereas some patients from far flung areas were mentally unprepared to get their discharge early. It was experienced that there was need to motivate and tell patients about the real benefits of laparoscopic varicocelectomy including early discharge from hospital. In our series the average time taken to return to routine work was 4.46 days (range 2-8 days), comparable to relevant literature.

In the follow up period extending from 7 days to 3 months no significant complications were noticed. On interaction with the patients included in the study in the follow up clinics, it was observed that patients with laparoscopic varicocelectomy were satisfied with their treatment. Recurrence was observed in one patientduring follow-up period. G Ali Shamsa et al. [12] reported recurrence in $2(6.7 \%)$ patients of laparoscopic group but it was not observed in patients who underwent open varicocelectomy. Podkamenev V V et al. [13] reported relapse rates of $1.84 \%$ in laparoscopic group and $1.36 \%$ in open varicocelectomy group. Recurrence in our study was which is concurrent with the available literature.

The improvement in quality of semen was analyzed and compared with the pre-operative semen analysis. Pre-operative semen analysis was done 1 week prior to surgery and then post operative semen analysis was advised 3 months after 
varicocelectomy . In the present series we found that the mean improvement in sperm concentration was 8.9 million/ml. The mean percentage of improvement in sperm motility was approx. 5.5\%. Al-Kandhari AM et al. [14] found that improvement in sperm motility and/or concentration was comparable and observed in $65 \%, 67 \%$, and $76 \%$ of the open, laparoscopic, and micro-surgical groups, respectively. Also, the pregnancy rate at 1 year was not significantly different and was $28 \%, 30 \%$, and $40 \%$ in three groups, respectively. Similar results are supported by various relevant studies [2,15]. Laparoscopic approach carries lesser post-operative morbidity; less post-operative pain with early return to work and in case of bilateral varicocele opposite side is dealt through the same ports. Therefore if facilities are available for this procedure and once perfection occurs in this minimally invasive technique, this is the procedure that gives lot of satisfaction to the patients as well as the operating surgeon.

\section{Conclusion}

Analyzing various parameters of these 39 patients and postoperative interaction with them over a period of time, it was observed that the results of laparoscopic varicocelectomy were comparable to open technique with minimum morbidity, shorter hospital stay and early return to work with the advantage of treating bilateral varicoceles without any additional incisions. Also laparoscopic varicocelectomy produces better overall patient satisfaction and hence can be considered as a preferable surgical technique in the management of symptomatic varicoceles.

\section{References}

1. Campbell-Walsh, text book of urology ( $9^{\text {th }}$ edn). (International ed.) Saunders Elsevier publishers, 127: pp 3794-3797.

2. Bebars GA, Zaki A, Dawood AR, El-Gohary MA (2000) Laparoscopic versus open high ligation of the testicular veins for the treatment of varicocele. JSLS 4(3): 209-213.

3. Barroso U Jr, Andrade DM, Novaes H, Netto JM, Andrade J (2009) Surgical Treatment of varicocele in childern with Open with Laparoscopic Palomo technique: a systemic review of the litrature. J Urol 181(6): 2724-2728.
4. Oraei Abbasian F (2010) comparison of two methods of varicocele diagnosis (upper and supinepositions) with color Doppler ultrasonography, thesis for the degree of doctorate in medicine, supervised by Shamsa A, Nekuei C, Shakeri MS . MUMS

5. Alaa Hatem Abdulkareem (2009) Laparoscopic versus various types of open ligations of the testicular veins for the treatment of varicocele. World Journal of Laparoscopic Surgery 2(1): 40-41.

6. Gouda El-labban (2011) Results of varicocele surgery: A comparison of laparoscopic and conventional open high ligation. Egyptian Journal of Surgery 30(1).

7. Al-Shareef ZH, Koneru SR, Al-Tayeb A, Shehata ZM, Aly TF, et al. (1993) Laparoscopic ligation of varicocele: An anatomically superior operation. Ann R Coll Surg Engl 75(5): 345-348.

8. Jiménez Garrido A, García de la Torre MV, Sánchez de Badajoz E (1999) A decade laparoscopic varicocelectomy: Cost and learning stages. Arch Esp Urol 52(3): 245-248.

9. Ogura K, Matsuda T, Terachi T, Horii Y, Takeuchi H, et al. (1994) Laparoscopic varicocelectomy: invasiveness and effectiveness compared with conventional open retroperitoneal high ligation. Int J Urol 1(1): 62-66.

10. Dudai M, Sayjan J, Mesholan J, Sperber Y (1995) Laparoscopic simultanous ligation of internal and external spermatic veins for varicocele. J Urol 153(3 Pt 1): 704-705.

11. Osman T, El-shourbay, Moustafa H, W Maged (2004) Laparoscopic versus open retroperitoneal bilateral varix ligation for obese patients presenting with primary sub-fertility: a randamized comperative study. African J of Urology 10(1): 50-57.

12. Shamsa A, Mohammadi L, Abolbashri M, Shakeri MT, Shamsa S (2009) Comparison of open and laparoscopic varicocelectomies in terms of operative time, sperm parameters, and complications. Urol J 6(3): 170175.

13. Podkamenev VV, Stalmakhovich VN, Urkov PS, Solovjev AA, Iljin VP (2002) Laparoscopic surgery for Pediatric varicoceles: Randomized control trial. J Pediatr Surg 37(5): 727-729.

14. Al-Kandari AM, Shabaan H, Ibrahim HM, Elshebiny YH, Shokeir AA (2007) Comparison of outcomes of different varicocelectomy techniques: open inguinal, laparoscopic and subinguinal microscopic varicocelectomy: A randamized clinical trial. Urology 69(3): 417-420.

15. Osman T, El-shourbay, Moustafa H, W Maged (2004) Laparoscopic versus open retroperitoneal bilateral varix ligation for obese patients presenting with primary sub-fertility: a randomized comperative study. African J of Urology 10(1): 50-57.

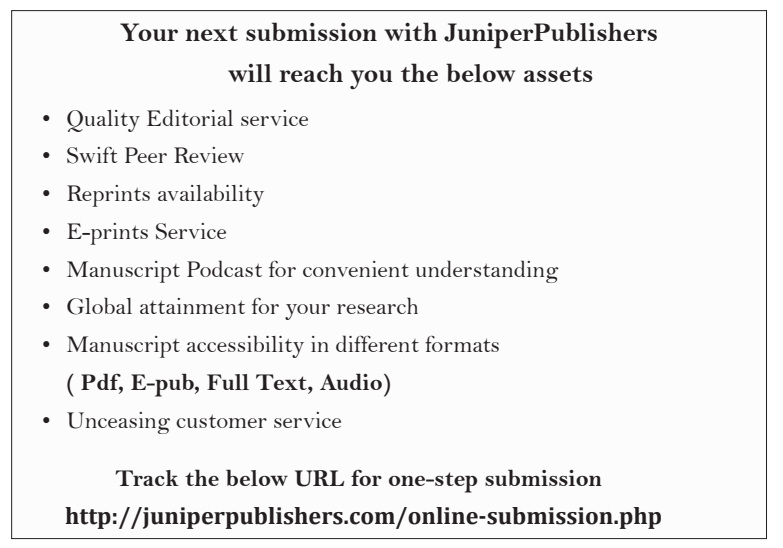

